\title{
The Bearable Lightness of Uncertainty
}

\author{
Denise L. F. Davis, MD and Calvin L. Chou, MD, PhD
}

University of California, and Veterans Affairs Healthcare System, San Francisco, Department of Medicine, San Francisco, CA, USA.

J Gen Intern Med 34(11):2293-4

DOI: $10.1007 / \mathrm{s} 11606-019-05191-4$

(c) Society of General Internal Medicine (This is a U.S. government work and not under copyright protection in the U.S.; foreign copyright protection may apply) 2019

$I^{n}$ $\mathrm{n}$ this issue of JGIM, Simpkin and Armstrong ${ }^{1}$ share a narrative review examining the gaps in understanding best practices of communicating uncertainty with patients. Specifically, they raise two different types of uncertainty: aleatoric uncertainty, due to random variations of disease incidence or outcomes as well as potential risks and benefits to individuals, and epistemic uncertainty, attributable to application of inadequate scientific knowledge. They then describe useful current strategies to help providers navigate this challenging area of communication and delineate a robust research agenda for optimal and helpful approaches. While we agree overall with this conceptualization of the provider's perspective of approaching uncertainty, thoughtful communication additionally requires not only a keen personal awareness but also a relational outward component with the people with whom we hope to communicate. We will expand here on both of these less heralded, and crucial, aspects of communication.

When invoking aleatoric or epistemic uncertainty, the authors focus on the internal cognitive and emotional fabric of the provider in isolation. But add relational difficulty in contentious or emotional interactions, disagreements over treatment (opiate prescription or restriction is currently the emblematic example), or complex diagnostic uncertainty, and the provider's personal awareness in achieving understanding of what we bring to the encounter and how it might affect it, becomes critical. ${ }^{2}$ Our choice to approach uncertainty with intention and compassion, or to allow ourselves to become defensive, distracted, or emotionally hijacked, can indelibly alter outcomes of the encounter.

Importantly, the provider is not the only actor in the play. Patients bring emotions and information about their conditions gleaned from not only their internal reflection but also friends, family, and the torrent of online information. Additional uncertainty arises from the interaction itself, the liminal space that represents the relationship between patient and provider: how will the patient metabolize the information we deliver, and how will we react in turn to that reaction? In Simpkin and Armstrong's framework, these may be classified as aspects of aleatoric uncertainty, but in the moment, the provider is not

Published online September 11, 2019 thinking about what kind of uncertainty this is - to be most effective, we must identify and empathize with the patient's emotions, clearly explain what can be explained, communicate uncertainty, handle the reactions of the patient (and caregivers), and attend to our own emotions, reactions, and reminders of similar prior situations. All of this simultaneous cognitive and emotional load can and often does overwhelm. Therefore, ironically, significant uncertainty exists about how to communicate uncertainty optimally in ways that reinforce the patient-provider relationship, patient autonomy, health outcomes, and provider resilience. Additionally, the everexpanding universe of medical knowledge, and the revision of paradigms previously considered sacrosanct (for example, daily aspirin in primary prevention of cardiovascular disease $^{3}$ ), constantly shifts the boundaries of certainty and uncertainty. Newer ways of including patients in shared decision-making conversations, including transparently using decision aids or risk calculators to collaborate on an ultimate treatment plan, ${ }^{4} 5$ are beginning to address some of the epistemic uncertainty in some of these complex decisions. Again, however, at the same time that we may decrease epistemic uncertainty, we may increase a form of aleatoric uncertainty: the sheer amount of information may overload patients, preventing them from grasping nuances to make a truly informed decision.

An additional level of complexity arises from interactions with patients who belong to marginalized groups including people of color, older patients, the uninsured, and women, who may have lower tolerance for ambiguity. ${ }^{6}$ Repeated experiences of bias, trauma, and lower quality of care certainly reduce trust and require additional attention and skills from physicians in order to co-create equity in decision-making processes. Even in the most straightforward of conversations, how well are physicians trained to invite conversations with patient about mistrust, perceptions of bias, and important aspects of transference that can impact patient trust? Associated with these marginalized groups is the commonly experienced situation of stereotype threat, an anxiety state that can undermine performance as individuals strive to avoid negative stereotypes about their identity. This effect creates cognitive load and can interfere with discussions of uncertainty: patients may wish to avoid being seen as vulnerable, and physicians want to avoid being seen as powerless. In Simpkin and Armstrong's framing, epistemic uncertainty may also increase when any healthcare team member may have difficulty accessing knowledge, a real effect of stereotype threat 
demonstrated in studies across many power and privilege differences. ${ }^{7}$ Additionally, aleatoric uncertainty can be the straw that breaks the proverbial camel's back in relationships with patients who fear that they will not get the care needed because of their identity. ${ }^{8}$

Ultimately, to help bridge the gaps and internal uncertainties and to supplement the strategies offered in the article, physician training in fundamental communication skills and advanced training in higher order skills should be the standard. In relationship-centered communication (RCC), the relationship between patient and clinician is valued as the "foundation of all healing and therapeutic activity". ${ }^{9}$ Clinical communication in general, and specifically in situations involving uncertainty, takes place in a matrix of relationships where there is much that is unknown. Several prominent health systems have undertaken large-scale efforts to support fundamental training in RCC with important outcomes demonstrating not only increased patient experience scores and decreased patient complaints, but also high provider satisfaction with training, increased provider empathy, and decreased provider burnout. ${ }^{10}$

We fully acknowledge that merely "getting everyone communication skills" is an overly simplistic and naïve goal, especially given some of the extraordinarily complex medical decisions and interpersonal interactions we face on a frequent basis. Yet, a reasonable grasp of fundamental communication skills, including positive affect, unrushed behaviors, inquiring about patient's preferences, and validating their right to make decisions can go a long way. In fact, these very behaviors improve satisfaction with visits for Black/African American patients. ${ }^{11}$ Eliciting patients' concerns, ideas about what might be causing their condition, and their expectations about their health care are skills that can be learned and practiced, can help increase diagnostic accuracy, and can aid the shared decision-making process. Fortunately, these apparent additions to the already time-pressured provider encounter may not actually require more time during many encounters. Indeed, data show that eliciting the full list of patient concerns at the outset of an encounter and explicitly addressing patients' emotions with empathy may actually save time. ${ }^{12,13}$ Emotional support should not be separate from information sharing and shared decisionmaking - instead, it should be included throughout the process of discussing options for diagnosis and treatment.

In a profession that continues to uphold knowledge and certainty as a significant value ("knowledge is power"), we risk the perception of powerlessness or even denigration if we reveal lack of certainty. We also pass on these values to our learners, who are already steeped in not merely the uncertainty inherent in clinical practice but also their own uncertainty with the limits of their own knowledge and skills. We will likely never resolve these multiple-edged complexities, and at the same time, by demonstrating - and teaching - authenticity and radical nondefensiveness, and by truly embracing our own vulnerability and imperfections, we may increase the likelihood (as uncertain as it might be) of ultimately achieving the connection that underpins the patientprovider relationship. Being honest with our colleagues, learners, and patients about how difficult uncertainty is to discuss, might allow patients and clinicians to share the burden of discomfort in the context of our relationships with each other.

Corresponding Author: Calvin L. Chou, $M D, P h D$; University of California, and Veterans Affairs Healthcare System, San Francisco, Department of Medicine, San Francisco, CA, USA (e-mail: calvin. chou@ucsf.edu).

\section{Compliance with Ethical Standards:}

Conflict of Interest: Drs. Davis and Chou receive honoraria for teaching for the Academy of Communication in Healthcare, a nonprofit organization.

\section{REFERENCES}

1. Simpkin AL, Armstrong KA. Communicating uncertainty: A narrative review and framework for future research. J Gen Intern Med 2019; https://doi.org/10.1007/s11606-019-04860-8.

2. Smith RC, Dwamena FC, Fortin AH 6th. Teaching personal awareness. J Gen Intern Med 2005;20:201-207.

3. Zheng SL, Roddick AJ. Association of aspirin use for primary prevention with cardiovascular events and bleeding events: a systematic review and meta-analysis. JAMA 2019;321:277-287.

4. Scalia P, Durand MA, Berkowitz JL, Ramesh NP, Faber MJ, Kremer JAM, Elwyn G. The impact and utility of encounter patient decision aids: systematic review, meta-analysis, and narrative synthesis. Patient Educ Couns 2019.

5. Kunneman M, Gionfriddo MR, Toloza FJK, Gartner FR, SpencerBonilla G, Hargraves IG, Erwin PJ, Montori VM. Humanistic communication in the evaluation of shared decision making: a systematic review. Patient Educ Couns 2019.

6. Han PK, Reeve BB, Moser RP, Klein WM. Aversion to ambiguity regarding medical tests and treatments: measurement, prevalence, and relationship to sociodemographic factors. J Health Commun 2009;14(6):556-72.

7. Schmader, T., Johns, M. (2003). Converging evidence that stereotype threat reduces working memory capacity. J Pers Soc Psychol, 85(3), 440452 .

8. Stepanikova, I., Mollborn, S., Cook, K. S., Thom, D. H., Kramer, R. M. (2006). Patients' Race, Ethnicity, Language, and Trust in a Physician. J Health Soc Behav, 47(4), 390-405.

9. Beach MC, Inui T, Relationship-Centered Care Research Network. Relationship-centered care. A constructive reframing. J Gen Intern Med. 2006;21 Suppl 1(Suppl 1):S3-8.

10. Boissy A, Windover AK, Bokar D, Karafa M, Neuendorf K, Frankel RM, Merlino J, Rothberg MB. Communication skills training for physicians improves patient satisfaction. J Gen Intern Med 2016;31:755-761.

11. Cooper LA, Roter DL, Johnson RL, Ford DE, Steinwachs DM, Powe NR. Patient-Centered Communication, Ratings of Care, and Concordance of Patient and Physician Race. Ann Intern Med;139:907-915

12. Marvel MK, Epstein RM, Flowers K, Beckman HB. Soliciting the patient's agenda: have we improved? JAMA 1999;281;283-287.

13. Levinson W, Gorawara-Bhat $\mathbf{R}$, Lamb J. A study of patient clues and physician responses in primary care and surgical settings. JAMA 2000;284; 1021-1027.

Publisher's Note Springer Nature remains neutral with regard to jurisdictional claims in published maps and institutional affiliations. 